\title{
Improving thermal performance of offices in JUST using fixed shading
}

\section{devices}

\author{
Ahmed A. Y Freewan* \\ Jordan University of Science and Technology, Irbid, Jordan \\ *. Tel: +962 796636130,Fax: +962 2 72010381, aafreewan@just.edu.jo (ahmedfreewan@hotmail.com)
}

\begin{abstract}
Large windows and highly glazed façades have been increasingly used in new buildings, allowing the access to daylight, solar gain and external view. Solar gain through non-shaded windows and glazed facades extremely increases the air temperature in summer especially in hot climates regions, like Jordan. Therefore, it affects thermal comfort, increase the cooling load and become a s ource of glare which harms the visual environment. Generally, shading devices are used to protect inner spaces from direct solar gain through openings, windows and glazed surfaces. The current research examined the effect of using shading devices on thermal environment and air temperature in offices facing south-west façade at Jordan University of Science and Technology (JUST). In such orientation windows required especial considerations to control solar gain in summer and winter. The research used real experiments to study effects of shading devices on thermal comfort. Three fixed shading devices; vertical fins and diagonal fins and egg crate, were installed in three identical offices. Thereafter, the air temperature was monitored and compared to non-shaded office. The results showed that the temperature in offices with shading devices compared to the office without shading devices was reduced to acceptable level. At the time of measurements diagonal fins perform better compared to other shading devices.
\end{abstract}

Keywords: Shading devices, Thermal comfort, Cooling load.

\section{Introduction}

\subsection{Shading devices}

Building around the world required a large amount of energy for cooling, heating and lighting. Well-building design requires integration of many factors, such as orientation shading devices and building form, to compromise energy consumption through a building. In additions windows, glazed façades and openings have an important role in building energy consumption whether for heating, cooling or lighting. Highly glazed façades and large windows have been increasingly used in new buildings, allowing the access to daylight, solar gain and external view. Therefore, their impact on cooling, heating and lighting demand in the building is significantly needed to be considered in building design. Proper shading design can contribute well to indoor illumination from daylight, improve thermal comfort, control solar heat gains and reduce glare at the same time as keep the view out.

Datta [1] studied the effect of using shading devices on thermal performances of buildings in Italy. The study used TRNSYS computer simulation to study many variables related to horizontal shading devices in different cities in Italy. It found that well shading devices could help save energy and improve thermal performance of buildings. Palmero-Marrero and Oliveira [2] studied the effect of using shading devices on thermal performance in many cities, around the world, with different latitude and climatic conditions using TRNSYS. The study showed that shading devices have a great impact on saving energy and improving thermal performance in offices in different climatic conditions. Bessoudo and other [3] and Tzempelikos and other [4,5] studied how shadings devices effect the thermal comfort in offices with glazed façades in cold climate in Montreal-Canada. They studied interior glazing and shading devices temperature, operative temperature and radiant temperature under different variables such as: Venetian blind, roller shade, and blind rotated angles. The study showed that shading devices could improve the thermal condition in cold and sunny conditions. They also developed a transient building thermal model. However, many 
researchers have studied the effect of using of shading devices on thermal comfort, energy consumptions and daylight performance of buildings [6-13].

The literature review has shown the need for studying the effect of shading devices on real building in regions with hot summer and cold winter like Jordan. The current research will investigate the effect of using of shading devices in south-west façade of offices in Jordan University of Science and Technology (JUST) on thermal conditions and air temperature.

\subsection{Case Study}

Jordan is classified as subtropical area, which is characterized by hot and dry summer and cold winter. Clear sky conditions dominate around the year with medium to overcast sky and moderate rainfall in winter. The average direct sun component is generally about eight hours a day. The major characteristic of Jordan's climate is the contrast between a relatively rainy season from November to April and dry weather for the rest of the year. The country has a long summer with a peak in August while January is the coolest month.

Jordan University of Science and Technology (JUST) is in Irbid (latitude $31.9^{\circ}$ North, longitude $35.9^{\circ}$ East) around $80 \mathrm{~km}$ to the north of Amman. The campus was designed by the Japanese architect Kenzo Tange. Buildings were constructed using prefab concrete panels and blocks. Office are on second floors, while ground and first floors used for lectures halls and labs respectively. The plan of the office levels, like wing A3 level 3, is double loaded corridor with offices at each side. The number of offices in south-west facade is 11 offices; each office is $3.5 \mathrm{~m}$ width, $4.25 \mathrm{~m}$ deep and $2.75 \mathrm{~m}$ high as seen in figure (1). The façade height comprised three sections; $0.80 \mathrm{~m}$ sills, $1 \mathrm{~m}$ windows and $0.5 \mathrm{~m}$ upper windows figure (2).

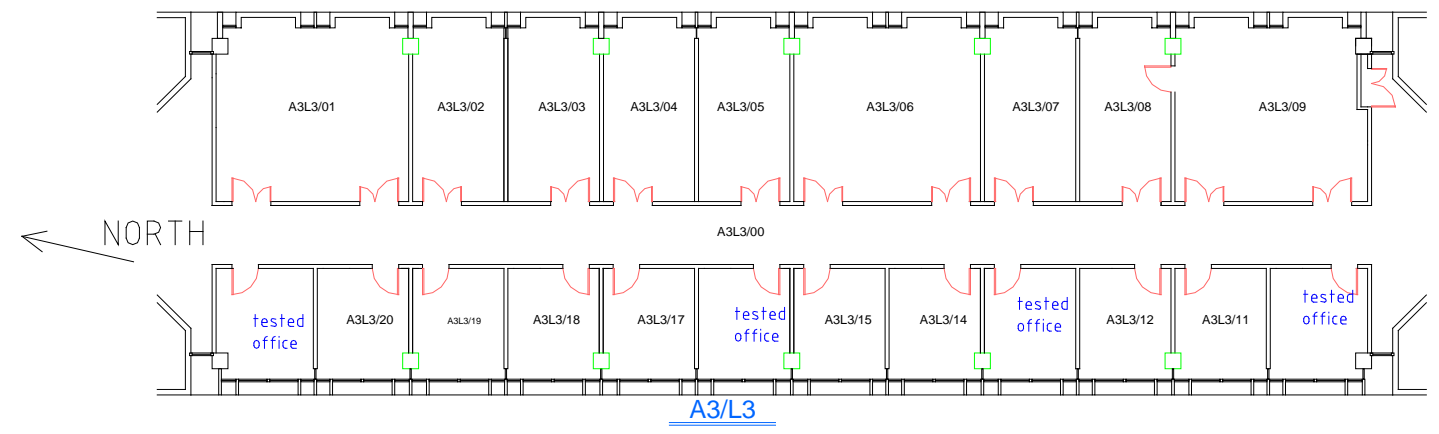

Figure 1 plan of offices level 3 wing A3 at JUST

Buildings oriented toward south-west with large windows area such office spaces in wing A3 at JUST suffer from uncontrolled solar gain throughout the year. In such orientation windows required especial considerations to control solar gain in summer and winter. The offices in wing A3-L3 at JUST expose to direct sunrays from noontime to sunset. The total hours of exposing is more than seven hours in summer raising the air temperature to intolerable level. Sunny area starts increasing gradually inside the offices from noontime to cover most of the office area thereafter as seen in figure (3).

\subsection{Current situation}

Author noticed that offices oriented to south-west such as offices in wing A3 experiencing high indoor temperature during sunny days at the same time lack of sufficient daylight due to occupants reactions. 

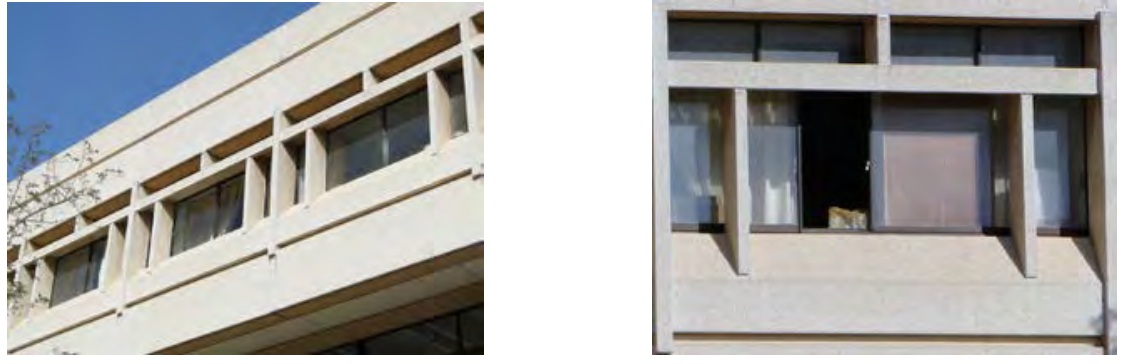

Figure 2 office façade (left), single office’ windows details ( right)

Occupants' reactions to discomfort almost have negative impact from energy view. Users spontaneously used curtains to overcome the problems shaped by large glazing area, especially the increasing sunny area, to block the direct sunrays and to avoid glare figure (3). So, the daylight level inside the offices decreased that needed auxiliary artificial light to keep the light level up to the needed task level. Curtains are $40 \mathrm{~cm}$ from the window because of architectural design details. Therefore, they could block the direct sunrays, but the heat gain inside the offices will remain with same rate. It will heat up the space between the curtains and the windows which automatically raise the temperature inside the whole office by direct gain, re-radiation and convection currents. F igure out a solution that overcoming such problems needs blocking the direct sunrays from outside before reaching the windows by shading device.

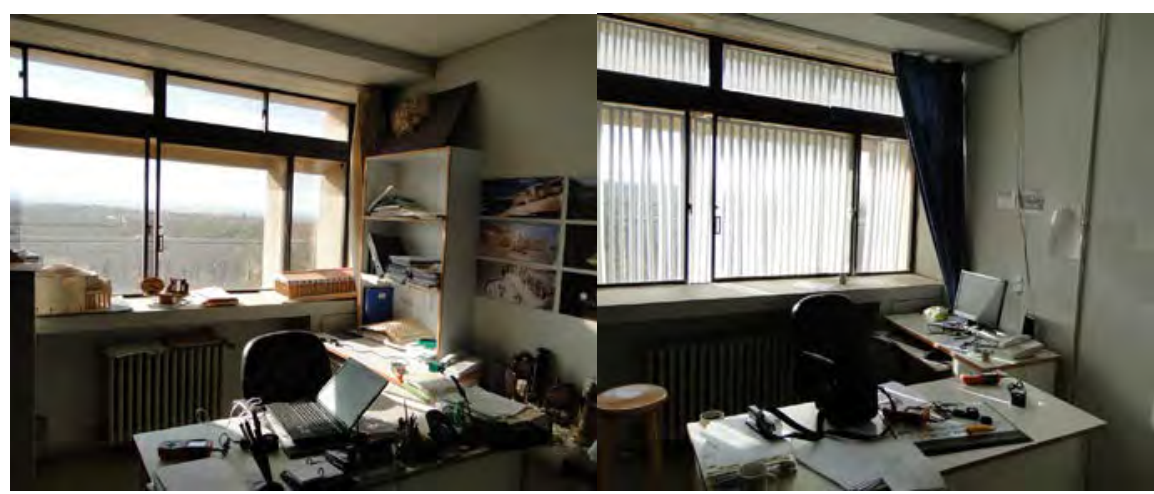

Figure 3 sunny area in the office without shading devices (left) the office with vertical fins (right)

\section{Experiment set up}

Three fixed temporary shading devices; egg-crate, vertical fins and diagonal fins, were installed in three offices. Thereafter, experimental measurements were conducted in three offices with different common shading devices, in addition to a base case office, an office without shading devices being installed. The offices are identical in all parameters like; area, geometry, orientation, windows design, glazing area and transmittance ratios, function, opening and surfaces material. The exposed façade of the tested offices is oriented to 12 south of the west.

Experimental measurements were taken in offices spaces on fully sunny days. Accordingly, measurements from tested offices fitted with the selected shading devices were compared to the measurement of the base case.

The dimensions and materials of these temporary devices were preliminary designed to keep the original building without major change to ease installing the devices in order to set the requirements of the permanent design. This is a part of long-term program aims at improving 
environmental and climatic conditions of JUST buildings to improve thermal conditions, visual environment and reduce energy consumptions. The next step of the research will be to study natural lighting environment and thermal comfort to compromise between thermal comfort, visual environment and energy saving. And so, the current research will be an initial stage for the long-term program to design the permanent shades to compromise between building changes and energy saving. Indoor air temperatures were measured using precalibrated thermometer. Data were collected every five minutes using EXTECH thermometer.

Vertical slats of $10 \mathrm{~cm}$ width were arranged with a small gap of $5 \mathrm{~cm}$ between the slats to admit some light, provide a view and allow for ventilation. They were not adjustable or designed to be angled. Diagonal fins consist of vertical fins of $30 \mathrm{~cm}$ width rotated at $45^{\circ}$ with a gap of $17 \mathrm{~cm}$ between the slats. Egg crate consists of verticals slats and horizontal louvers of $10 \mathrm{~cm}$ width. Vertical slats were arranged with a gap of $15 \mathrm{~cm}$ between the slats and horizontal parts with $7.5 \mathrm{~cm}$ between the louvers. It could admit light, provide a view to outside and allow for ventilation.

\section{Results}

Figure 4 (left) shows the results of air temperature in office with vertical fins compared to the base case. Clearly, using vertical fins help reduce the inner temperature compared to non shaded office. It helped reduce air temperature up $17 \%$ in the afternoon with an average of $9 \%$. In the morning the air temperature almost closed in both offices, while the difference start to increase gradually as the sunrays start reaching the windows as seen in figure (3). Generally verticals fins reduce the air temperature in the period from $1 \mathrm{pm}$ to $4 \mathrm{pm}$ by an average of $4 \mathrm{C}^{\circ}$ with maximum reduction by $7 \mathrm{C}^{\circ}$. On the other hand, diagonal fins as seen in figure 4 (right) reduced the air temperature by up to $21 \%$ compare to the base case with an average of $13 \%$. The difference in the morning is neglected while it $\mathrm{s}$ tarts to increase dramatically from $12 \mathrm{pm}$ to $4 \mathrm{pm}$. The maximum decrease occurred after $3 \mathrm{pm}$ by $8.5 \mathrm{C}^{\circ}$. Figure 5 (left) shows how the egg-crate shading improves the thermal performance of the office. It reduced the air temperature by an average of $12 \%$ in the period from $12 \mathrm{pm}$ to $4 \mathrm{pm}$ compare to the base case. Between $3 \mathrm{pm}$ and $4 \mathrm{pm}$ it reduced the air temperature by $8 \mathrm{C}^{\circ}$.
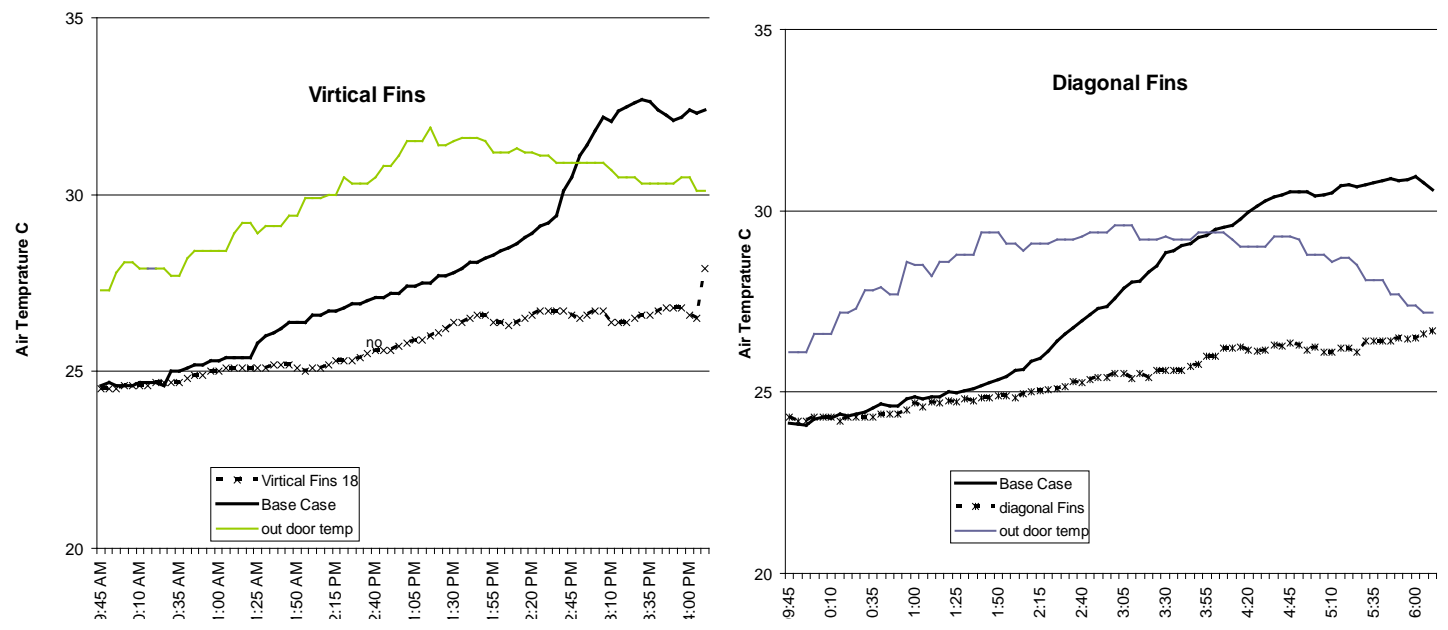

Figure 4 air temperature in office with vertical fins compared to the base case (left) air temperature in office with diagonal fins compared to base case. 

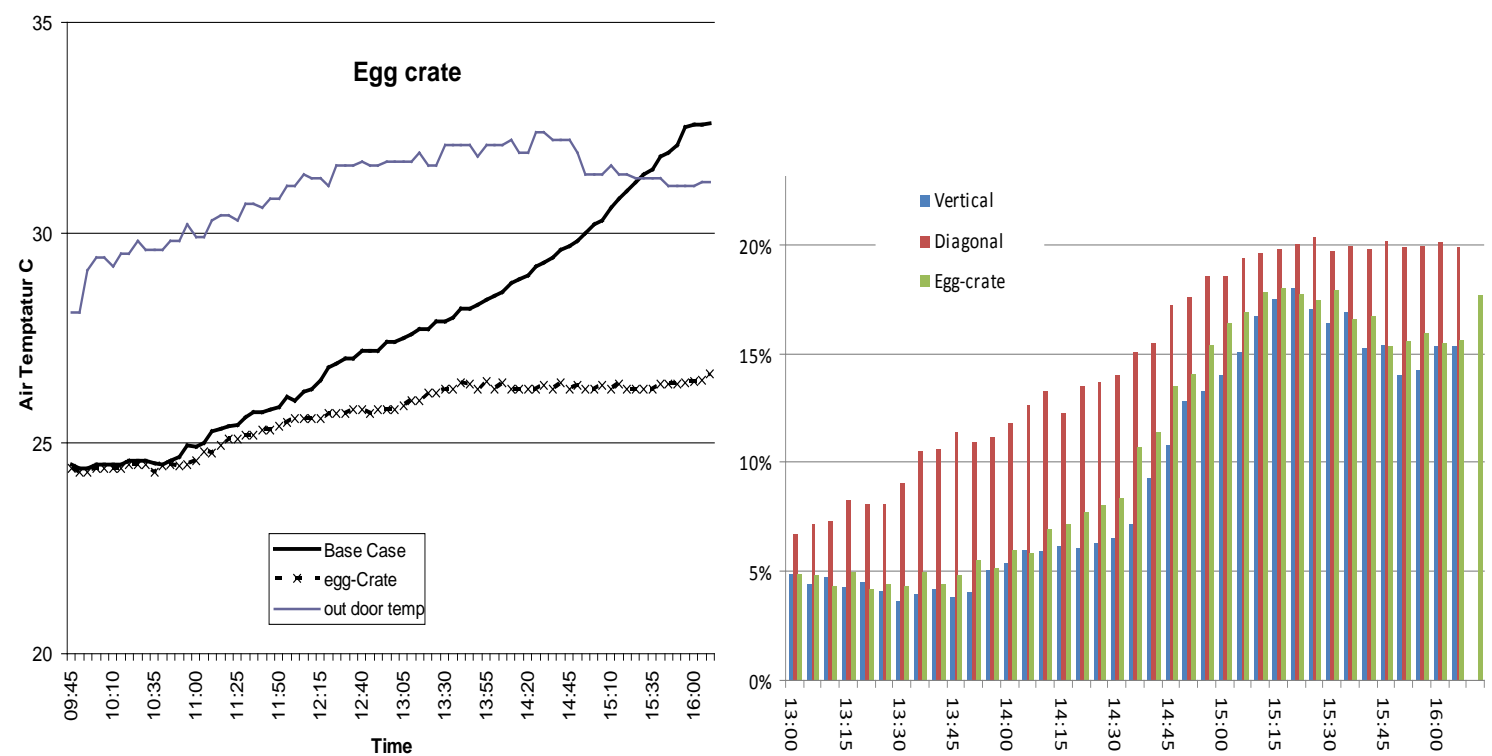

Figure 5 air temperature in office with egg-crate compared to base case and outdoor temperature (left) shows the percentage of reduction in air temperature as a result of using shading (right)

Figure 5 (right) shows the percentage of reduction in air temperature as a result of using shading compared to the base case office. It clearly can be inferred the diagonal fins performed better than verticals and egg-crate in the period from $1 \mathrm{pm}$ to $3 \mathrm{pm}$ during the period of measurement in September and October.

Graphically analysis of applying shading and shade angles on sundial diagrams show how each type of shading devices perform around the year. Table 1 shows how the shading devices will perform all the time according to solar angles, altitude and azimuth, during the time of the experiments. Diagonal fins will block all sun rays while vertical fins will block the sunrays in the period $12 \mathrm{pm}-1 \mathrm{pm}$ and $2 \mathrm{pm}$ to $4 \mathrm{pm}$ and allow the sunrays to enter the offices from $1 \mathrm{pm}$ to $2 \mathrm{pm}$. Egg-crate shading will allow sunrays to enter the offices between 1:30pm to $3 \mathrm{pm}$ and block before and after that.

Studying the performance of shading devices around the year shows that verticals fins partially shade inner spaces in the period from October to February and allow sun to reach inner spaces after $2 \mathrm{pm}$. In contrast, it allows the sunrays to reach the inner spaces in the hot period of the year, March to September, and in the hot time of the day from 1:30pm to 3:30 pm. Diagonal fins fully shade inner spaces in the period October to March and partially in the period April to September. It will block the sunrays only before $1 \mathrm{pm}$ in the period from May to July when the shading are crucially needed. Egg-crate will perform well in hot period and allow for sun rays to enter inner spaces in such orientation in cold period. The analysis of the results show, that well shading design could help improve the thermal performance of the offices oriented to south-west. 
Table 1 Installed shading devices and shading angles with sundial diagrams

\begin{tabular}{|l|l|l|l|l|}
\hline & Snstalled shading devices & Shade angles & Sundial Diagrams \\
\hline $\begin{array}{l}\text { Diago } \\
\text { Fal }\end{array}$ &
\end{tabular}

\section{Discussion and Conclusions}

This paper summarizes the experimental results of thermal environment and air temperature in highly glazed offices with shading devices. In general, results indicate a major influence of shading on s olar gains and thermal performance of offices. All shading devices helped improve the thermal environment in the offices in time of the experiments in September and October. It is clear that until $1 \mathrm{pm}$ all shading devices reduced the air temperature approximately with same rate. On the contrary, after $1 \mathrm{pm}$ the diagonal shading devices performed better as it helped block all the sunrays all the time. On the other side, vertical fins and egg-crate shading devices allowed some part of sun shine to enter the offices in the period $1 \mathrm{pm}-3 \mathrm{pm}$.

Designing of shading devices requires taking into consideration around the year measurements in both hot and cold periods. Therefore, egg-crate shading devices could perform well around the year if the horizontal part extends to the outside by the half of the 
current width. It will block the sunrays in hot period and allow it to enter in cold period. Diagonal fins will completely block the sun rays in the clod period when the sun is crucially required it cloud perform well in intermediate period such as in September. Moreover, diagonal fins block the view to outside while egg-crate will allow for kind of connections to outside. Modified egg-crate could go well with current situation, fewer modifications, as vertical slats of small width can be easily installed on the window sills and horizontal part can be fixed on vertical slats. Further studies are required to study the effect of shading devices on daylight, visual environment and view out.

\section{References}

[1] Datta, G., Effect of fixed horizontal louver shading devices on thermal performance of building by TRNSYS simulation. Renewable Energy 23, 2001, p. 497-507.

[2] Palmero-Marrero, A.I. and A.C. OLiveira, effect of louver shading devices on building energy requirements Applied Energy 87, 2010, p. 2040-2049.

[3] Bessoudo, M., et al., Indoor thermal environmental conditions near glazed facades with shading devices e Part I: Experiments and building thermal model. Building and Environment 45, 2010, p. 2506-2516.

[4] Tzempelikos, A., et al. the impact of shading devices on the thermal comfort conditions in perimeter zones with glass facades. in 2nd PALENC conference and 28th AIVC conference on building low energy cooling and advanced ventilation technologies in the 21st century. 2007, Crete Island, Greece,P 1072-1077

[5] Tzempelikos, A., et al., Indoor thermal environmental conditions near glazed facades with shading devices e Part II: Experiments and building thermal model. Building and Environment 45, 2010. p. 2517-2525.

[6] Freewan, A.A., L. Shao, and S. Riffat, Interactions between louvers and ceiling geometry for maximum daylighting performance. Renewable Energy 34, 2009, p. 223-232.

[7] Tzempelikos, A. and A.K. Athienitis, The impact of shading design and control on building cooling and lighting demand. Solar Energy 81, 2007, p. 369-382.

[8] Chou, C.-P., The Performance of Daylighting with Shading Device in Architecture Design. Tamkang Journal of Science and Engineering 7, 2004, p. 205-212.

[9] Dubois, M.C., Shading devices and daylight quality: an evaluation based on s imple performance indicators. Lighting Research and Technology 35, 2003, p. 61-76.

[10]Lee, E.S., D.L. DiBartolomeo, and S.E. Selkowitz, Thermal and daylighting performance of an automated venetian blind and lighting system in a full-scale private office. Energy and Buildings 29(1), 1998, p. 47-63.

[11]Wong and I. Agustinus Djoko, Effect of external shading devices on daylighting penetration in residential buildings. Lighting Research and Technology 36, 2004, p. 317333.

[12] Sutter, Y., D. Dumortier, and M. Fontoynont, The use of shading systems in VDU task offices: A pilot study. Energy and Buildings 38, 2006, p. 780-789.

[13] Yoo, S.-H. and E.-T. Lee, Efficiency characteristic of building integrated photovoltaics as a shading device. Building and Environment 37, 2002, P. 615-623. 